\title{
Galos em Combate na Paraíba O Descumprimento da Legislação Ambiental
}

\author{
Marco Lunardi Escobar \\ Doutor em Recursos Naturais pela Universidade Federal \\ de Campina Grande-PB. Professor de Direito da Univer- \\ sidade Potiguar. Professor de Comunicação Social da \\ Universidade do Estado do Rio Grande do Norte. mar- \\ coescobar@unp.br
}

\section{José Otávio Aguiar}

Doutor em História e Culturas Políticas pela Universidade Federal de Minas Gerais. Pós-doutor em História, Relações de Poder, Sociedade e Ambiente pela Universidade Federal de Pernambuco. Professor da Universidade Federal de Campina Grande/PB no curso de História, e nos programas de Pós-Graduação em História e em Recursos Naturais. otavio.j.aguiar@gmail.com

\section{Paula Apolinário Zagui}

Mestre em Ambiente e Desenvolvimento Regional pela Universidade Federal de Mato Grosso. Professora da Universidade Estadual do Rio Grande do Norte. Especialista em Didática do Ensino Superior. Graduada em Comunicação Social - Habilitação Publicidade e Propaganda e Graduação em Sistemas para Web. paulazagui@uern.br

\section{Resumo}

Este texto, que faz parte do projeto de estudo concluído na Universidade Federal de Campina Grande, propõe-se a analisar aspectos sociais, legais e históricos das disputas de galos, práticas estas que datam da mais remota Antiguidade. A pesquisa aborda as permissões que a atual legislação cria para esta prática, comum na Paraíba. Nesse contexto, a atividade das brigas de galo se confronta com 0 dispositivo constitucional, o qual proíbe que animais sejam submetidos a práticas cruéis. Utilizou-se, para este estudo, pesquisa descritiva com entrevistas com os órgãos de proteção aos animais.

Palavras-chave: Galos. Rinhas. Prática. Paraíba. 


\title{
Cockfights in Paraiba: Violates Environmental Law
}

\begin{abstract}
This text, which is part of the study project completed at the Federal University of Campina Grande, it is proposed to analyze social, legal and historical cocks disputes, these practices dating from ancient times. The research addresses the permissions that the current legislation creates for this practice, common in the Paraíba. In this context , the activity of cockfighting is confronted with the constitutional provision, which prohibits animals from being subjected to cruel practices. It was used for this study, descriptive research with interviews with the oversight bodies to animals.
\end{abstract}

Keywords: Cocks. Cockfights. Release. Paraiba.

\section{Sumário}

1 Introdução. 2 Aspectos Históricos das Rinhas de Galo no Brasil. 3 A Cultura de Aceitação das Rinhas. 4 Galistas Ganham Decisão Judicial Favorável. 5 A Fauna que necessita mais garantias. 5.1 0 Princípio da Precaução. 6 Conclusões. 7 Referências. 


\section{INTRODUÇÃO}

O trabalho se propôs a analisar aspectos legais, históricos e sociais das disputas de galos, práticas estas que datam da mais remota Antiguidade. $\mathrm{O}$ projeto aborda as permissões que a atual legislação cria para esta prática, costumeiramente presente em comunidades da Paraíba.

Assim entendido, as rinhas de galo ainda são praticadas, com ou sem autorizações legais. O artigo analisa o aparente conflito entre os princípios ambientais e a liberdade de manifestação cultural que existe em relação às rinhas de galo. Verifica-se que estas práticas submetem os animais à crueldade e devem ser combatidas pelo Estado brasileiro. Existiria um confronto entre o meio ambiente físico ou natural - que inclui a fauna brasileira - e o meio ambiente cultural, que tutela as manifestações, festividades e eventos que utilizam os animais.

As normas ambientais podem permitir a realização de rinhas de galo ainda frequentes no Nordeste brasileiro. Como é possível admitir que o Judiciário conceda decisões favoráveis à manutenção das brigas de galos? Seria necessário a aplicação de medidas mais claras para se evitar controvérsias? Neste trabalho destaca-se que a legislação é clara, porém a atual gestão ambiental teria falhas nesse sentido.

Persiste ainda no país um costume histórico de se colocar espécies de aves para rinha, como forma de divertimento ou jogo com apostas.

Os caracteres históricos aqui apresentados estão relacionados a um ordenamento jurídico possivelmente permissivo para as rinhas de galo. Ainda que tenhamos as normas ambientais, é necessária a garantia de efetividade das normas do Direito Animal, para que as espécies não sejam expostas a riscos ou maus-tratos. 
A rinha de galo caracteriza uma manifestação cultural, tutelada também pelo Direito Ambiental, mas o meio ambiente físico ou natural deve prevalecer sobre os aspectos culturais, pois uma tradição de colocar os galos para brigar, em detrimento da fauna vítima de maus tratos, pode constituir ilegalidade, o que se pretende demonstrar neste artigo.

\section{ASPECTOS HISTÓRICOS DAS RINHAS DE GALO NO BRASIL}

A rinha chegou ao Brasil com os espanhóis, em 1530, e em seguida espalhou-se pelo território. Desde os primórdios a rinha de galo era normalmente realizada, sem proibições legais nem movimentações contrárias à prática (Lima, 2009).

O presidente Getúlio Vargas promulgou o Decreto Federal 24.645 em 10 de julho de 1934, o qual em seu artigo $3^{\circ}$ estabelecia medidas de proteção aos animais e foi determinada, no Brasil, a punição para os atos de "realizar ou promover lutas entre animais da mesma espécie ou de espécies diferentes, touradas e simulacro de touradas, ainda mesmo em lugar privado" (Brasil, 2011a).

Em 3 de outubro de 1941 foi baixado o Decreto-Lei 3.688, Lei de Contravenções Penais, que, em seu artigo 64 proibia a crueldade contra os animais (Brasil, 2011c). Na época levantou-se uma polêmica em torno do fato de a nova lei ter ou não revogado o Decreto Federal 24.645 promulgado por Getúlio Vargas. As discussões e a jurisprudência firmaram-se no sentido de que “em síntese”, os preceitos contidos no artigo 64 compreendem na sua quase totalidade todas aquelas modalidades de crueldade contra os animais contidas no Decreto 24.645/34.

Esta provocação de lutas entre galos envolve agressividade e crueldade que, quando não resulta em morte, acarreta a inutilização de partes do corpo, como olhos, pernas, asas, entre outros órgãos (Hirata, 2008, p. 44). 
$\mathrm{Na}$ última década esta prática, também considerada esporte, passou a preocupar as autoridades e ambientalistas em todo o país. Isso porque sua realização pode constituir crime de crueldade contra os animais, previsto no artigo 32 da Lei $n^{0} 9.605 / 98$, cuja pena vai de três meses a um ano de detenção, além do pagamento de multa. A pena sofre aumento se ocorre morte do animal (Brasil, 2008).

Ainda durante o governo Getúlio Vargas a Lei das Contravenções Penais e a proibição de jogos de azar geraram polêmica sobre a legalidade das rinhas, mas prevaleceu a liberdade para a prática pelos 20 anos seguintes. Em 18 de maio de 1961, porém, o presidente Jânio Quadros editou o Decreto $\mathrm{n}^{\mathrm{o}} 50.620 / 61$, proibindo expressamente a briga de galos:

Considerando que todos os animais existentes no País são tutelados do Estado;

Considerando que a lei proíbe e pune os maus-tratos infringidos a quaisquer animais, em lugar público ou privado;

Considerando que as lutas entre animais, estimuladas pelo homem, constituem maus-tratos;

Considerando que os centros onde se realizam as competições denominadas "brigas de galos" converteram-se em locais públicos de apostas e jogos proibidos,

Art. $1^{0}$ - Fica proibido em todo o território nacional, realizar ou promover "brigas de galo" ou quaisquer outras lutas entre animais da mesma espécie ou de espécies diferentes (Brasil, 2011b).

O decreto de Jânio Quadros ainda determinava que passava a ser proibido realizar ou promover espetáculos cuja atração fosse a luta de animais de qualquer espécie. A norma também definia que as autoridades promoverão o imediato fechamento das rinhas de galos e de quaisquer locais onde se realizam espetáculos desta natureza, e cumprirão as disposições referentes à punição dos infratores e demais medidas legais aplicáveis (Brasil, 2011b). 
O governo federal, dessa forma, demonstrou que a Lei de Contravenções Penais não proibia especificamente esta prática de colocar os galos em briga, pois se vedasse não seria necessário editar um decreto presidencial para proibir expressamente as rinhas de galo.

A proibição de Jânio Quadros ocorreu em uma época em que as práticas politicamente incorretas normalmente não eram registradas, e os cuidados com os animais eram considerados bizarrice. Dessa forma, a vedação foi parar nas manchetes da imprensa, provocando repúdio, pois as apostas giravam boas quantias de dinheiro nos locais em que as rinhas eram realizadas na capital paulista, por exemplo.

A segunda liberação veio um ano após a vedação. Em 1962 o então primeiro-ministro brasileiro Tancredo Neves editou o Decreto $\mathrm{n}^{\mathrm{o}} 1.233 / 62$, que revogou o anterior, o que permitiu novamente a prática das rinhas. A partir de 1962 foram 36 anos sob uma concessão velada por parte do poder público para a prática das brigas. Em 1998, com o advento da Lei $\mathrm{n}^{\mathrm{o}}$ 9.605/98, foram revogadas as leis e decretos anteriores que eram utilizados para coibir as rinhas de galo, pois tratavam de crimes ambientais e maus-tratos aos animais (Brasil, 2003).

\section{A CULTURA DE ACEITAÇÃO DAS RINHAS}

A rinha de galo é uma prática hoje considerada crime ambiental na principal legislação que protege os animais, pois o artigo 32 da Lei de Crimes Ambientais condena "o ato de abuso, maus-tratos, ferir ou mutilar animais silvestres, domésticos ou domesticados, nativos ou exóticos”, e prevê pena de detenção de três meses a um ano, além de multa (Brasil, 2008) 
Atualmente os órgãos ambientais realizam com alguma frequência o fechamento e apreensões em locais utilizados para rinha de galos no Nordeste brasileiro, inclusive em João Pessoa e nas maiores cidades do interior da Paraíba, como Santa Rita, Patos e Rio Tinto.

Nesta pesquisa, nas entrevistas junto aos órgãos fiscalizadores, revelou-se que é comum pessoas da alta sociedade, inclusive detentores de cargos eletivos, constarem entre os participantes e até organizadores das rinhas de galos realizadas na região. A presença de pessoas e apostadores de importância traz uma falsa ideia de legalidade desse tipo de evento, o que inibe até a atividade fiscalizatória e aplicação do poder de polícia para proibir a prática.

Figura 1 - Rinha realizada no interior da Paraíba

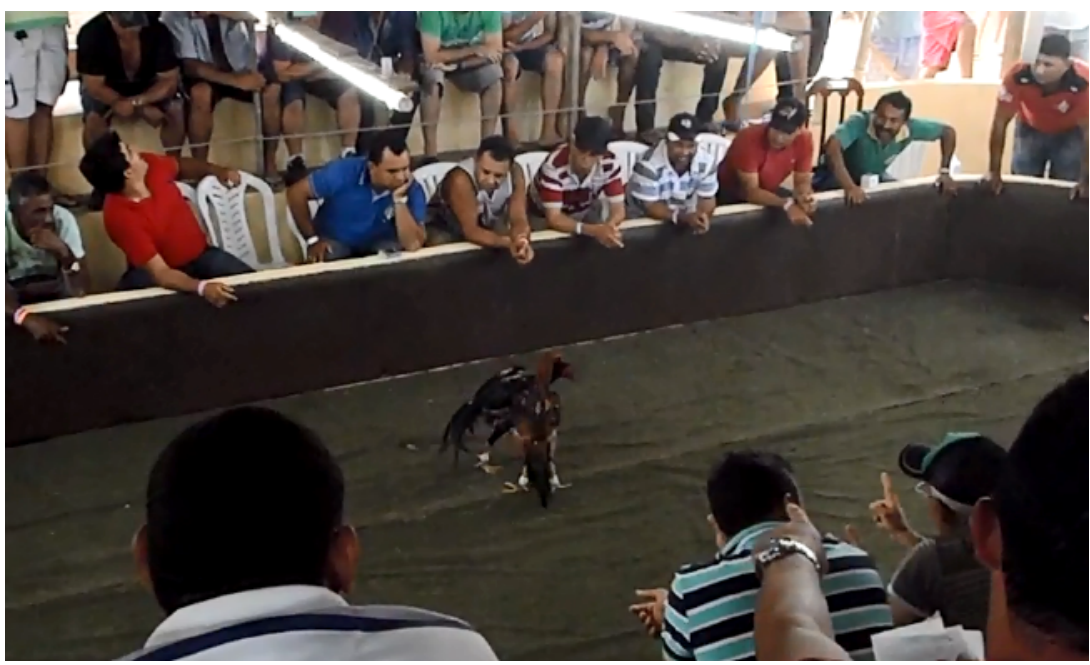

Fonte: Escobar (2014).

Percebe-se, então, o interesse dos grupos sociais envolvidos nas rinhas e uma tolerância pelo fato de integrantes do poder público estarem entre os participantes da atividade. Em uma análise um pouco mais aprofundada, é possível relacionar estes fatos à ideia firmada nas primeiras 
décadas do século 20, sendo gestada no cruzamento do que Durval Muniz de Albuquerque Júnior (2009) chama de "práticas regionalizantes”, sejam elas por interesses políticos ou culturais. Segundo o autor, o Nordeste é uma invenção recente na História brasileira.

Para Albuquerque Jr. (2009, p. 27), “a história se assemelha ao teatro, onde os atores, agentes da história, só podem criar a condição de se identificarem com figuras do passado, de representarem papéis, de vestirem máscaras, elaboradas permanentemente”.

O autor faz a reflexão acerca da região que sofre pelas determinadas visões impostas pela mídia e pela crítica cultural brasileira. Sobre o Nordeste, o historiador questiona a nossa própria postura em afirmar e reafirmar a concepção folclórica e regionalista que nós insistimos em definir como homogênea e unitária. Para exemplificar, o paraibano traz a época de festas juninas, ocasião em que a paisagem urbana das grandes cidades nordestinas é maquiada por uma falsa concepção rural.

Independentemente da literatura acerca dos costumes nordestinos, é senso comum de que nessa região do Brasil claramente ocorre - com ou sem autorização judicial - a realização das práticas de rinhas de galos. Dessa forma, necessário se faz um estudo da trajetória das permissões desta atividade, com ênfase nas decisões do Judiciário que historicamente já ampararam essa prática ora citada.

\section{GALISTAS GANHAM DECISÃO JUDICIAL FAVORÁVEL}

As brigas de galo na Paraíba podem ser promovidas de forma clandestina - como ocorre na maioria dos casos - ou de maneira oficializada por meio de liminares da Justiça. Na Paraíba o Judiciário já se posicionou favorável à realização das lutas. Em 14 de outubro de 2009 a juíza da $5^{\text {a }}$ Vara da Fazenda de João Pessoa, Maria de Fátima Lúcia Ramalho, permitiu 
a rinha, por entender que se trata de um esporte milenar e que a legislação brasileira não traria proibição, conforme o texto da sentença judicial publicado no Diário da Justiça (Paraíba, 2009). No início da sentença, a magistrada declara:

Ao contrário do que dizem os 'ambientalistas', o galismo está disseminado em todo o mundo (...), o esporte não visa mutilar, ferir ou maltratar os denominados 'galos de briga', mas tão somente fazer aflorar no animal suas características genéticas inerentes à luta territorial, raça e tudo mais. É assim com as vaquejadas, cavalgadas e rodeios, estes últimos, movimentam milhões e milhões de reais, a exemplo do tão famoso e conhecido Rodeio de Barretos.

A juíza de Direito deferiu liminar para atender mandado de segurança preventivo impetrado pela Associação de Criadores e Expositores de Raças Combatentes. A decisão também suspendeu as multas para quem fosse pego com galos de briga, que é de $\mathrm{R} \$ 2$ mil mais $\mathrm{R} \$ 200$ mil por animal envolvido. As pessoas flagradas com os animais ainda deixavam de ser enquadradas em crime ambiental, que prevê detenção de três meses a um ano (Paraíba, 2009).

A única entrevista que a juíza concedeu sobre a medida foi para o jornalista Maurício Gonçalves, da Gazeta de Alagoas. Maria de Fátima Ramalho defendia a atividade dos galistas, diz ter acompanhado criações de aves de perto. Para a juíza, as autoridades que ainda coíbem a prática das rinhas na Paraíba estariam desinformadas sobre o assunto (Gonçalves, 2011, p. 29):

Eu tive o cuidado de acompanhar as criações, presenciei in loco. Trata-se de um prática cultural milenar, que em outros países é regulamentada por lei, mas no Brasil não tem uma legislação própria. Muitas vezes, os animais apreendidos são até sacrificados, então me parece que o mau-trato maior é a morte (Gonçalves, 2011, p. 29). 
Pelas palavras da magistrada na entrevista, a questão cultural foi mesmo decisiva para tomar a medida de liberação. Dessa forma, a julgadora referia-se ao direito à cultura para o povo brasileiro. $\mathrm{O}$ disposto na Constituição Federal determina que:

Art. 215 - O Estado garantirá a todos o pleno exercício dos direitos culturais e acesso às fontes da cultura nacional, e apoiará e incentivará a valorização e a difusão das manifestações culturais.

$\S 1^{\circ}$ - O Estado protegerá as manifestações das culturas populares, indígenas e afro-brasileiras, e das de outros grupos participantes do processo civilizatório nacional (Brasil, 2008).

A defesa para a prática seria ainda no sentido de que os galos ficariam mais bem tratados se estivessem de posse dos criadores, pois corriam o risco de serem sacrificados em caso de apreensão pelas autoridades.

Para os órgãos ambientais, a decisão que autorizava a rinha na Paraíba não foi bem recebida. "Não foi de bom grado" declarou o comandante da Polícia Ambiental em entrevista a esta pesquisa (informação verbal).

$\mathrm{Na}$ época da decisão judicial favorável aos realizadores e apostadores das rinhas de galo, houve revolta por parte de alguns defensores da fauna brasileira, a exemplo da Associação Paraibana Amigos da Natureza, a Apan.

A reação da Associação foi incentivar o clamor público, observando que "a Apan também trabalha com a imprensa, isso foi bastante divulgado, várias tevês divulgaram, foi algo que saiu nacionalmente nos meios, isso também trouxe um respaldo para a nossa luta”, destacou a presidente da entidade Socorro Fernandes (informação verbal). ${ }^{1} \mathrm{Na}$ época a Associa-

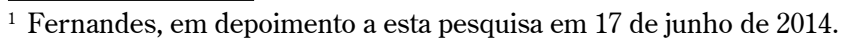


ção criticou a decisão liberatória argumentando que a Justiça não poderia esquecer que existem leis federais, estaduais e municipais que protegem a fauna.

A Associação provocou o Ministério Público Estadual e o Ibama, a fim de que tomassem providências. A partir disso, alguns locais para realização das rinhas foram desativados, e ainda há uma constante preocupação dos órgãos (informação verbal).

No dia 4 de novembro de 2009 o Instituto Brasileiro do Meio Ambiente e dos Recursos Naturais Renováveis pronunciou-se, por meio de uma nota pública. $\mathrm{O}$ então superintendente do órgão federal na Paraíba considerou que a decisão determinou que a Superintendência de Administração do Meio Ambiente - Sudema - "deve abster-se de proibir o livre exercício do esporte galismo" (sic).

O órgão declarou que a atuação de combate às rinhas de galo possui embasamento legal no Decreto-Lei n⿳0 24.645/1934, que caracteriza a realização ou promoção de lutas entre animais da mesma espécie ou de espécies diferentes como maus-tratos e que a Lei dos Crimes Ambientais no seu artigo 32 considera os maus-tratos como infração ambiental. Ainda entende a Superintendência do Ibama que esta prática inclusive é vedada pelo artigo 225 da Constituição Federal, dispositivo já exposto neste trabalho.

O texto da nota seguiu com mais contestações à decisão favorável às rinhas. Apontou que já foi declarada pelo Supremo Tribunal Federal a inconstitucionalidade de leis estaduais que autorizam a prática de rinhas de galo. Também considerou que a Justiça comum do Estado da Paraíba não poderia interferir diretamente na atuação do Ibama, que é órgão federal cuja atuação só poderia ser julgada pela Justiça Federal. Para completar, informou que "a fiscalização ambiental pode ser realizada por entidades 
municipais, estaduais e federais de modo supletivo”. Significa que, na falta de fiscalização por parte de uma ou mais esferas, um outro órgão ambiental pode atuar para evitar os danos/degradação ambiental.

Para o órgão federal de meio ambiente, a decisão em nada afetaria a posição de que era preciso manter os trabalhos de combate às rinhas. Ao final da nota pública o Ibama (2009) na Paraíba declarou

[...] a liminar concedida pela Juíza de Direito Dra. Maria de Fátima Lúcia Ramalho não impõe nenhuma proibição às ações do Ibama, portanto continuará atuando para coibir a realização de rinhas de galo em todo o Estado da Paraíba, impondo multas e embargando e interditando áreas.

E o órgão federal manteve as operações. No mesmo mês, em 23 de novembro de 2009, o Ibama proibiu o campeonato nacional de rinha de galos que era realizado em João Pessoa.

Como a liminar não interferiu nas ações do Ibama, a Superintendência deste órgão na Paraíba garantiu que continuaria fiscalizando esta prática criminosa. Superintendente do Ibama na Paraíba à época, Ronilson José da Paz, (informação verbal) ${ }^{2}$ declarou que desde 1934 as rinhas de galos são consideradas maus-tratos, sendo portanto entendidas como infração ambiental .

Já o órgão estadual, a Superintendência de Administração do Meio Ambiente do Estado da Paraíba, apelou da sentença apenas para informar que não é competente para fazer esse tipo de fiscalização e autuação.

Ao final, a prática das brigas de galo foi finalmente proibida no Estado pelo Tribunal de Justiça da Paraíba. No dia $1^{0}$ de setembro de 2011, a sentença foi reformada em votação por unanimidade na instância superior do Judiciário Estadual (Paraíba, 2011). A Primeira Câmara Cível

${ }^{2} \mathrm{Paz}$, em depoimento a esta pesquisa em 14 de setembro de 2013. 
do Tribunal de Justiça decidiu pela proibição da prática das brigas de galo na Paraíba, cabendo à Superintendência de Administração do Meio Ambiente - Sudema - a fiscalização das possíveis práticas de maus-tratos.

A decisão colegiada do Tribunal paraibano reformou a sentença da $5^{\text {a }}$ Vara da Fazenda Pública de João Pessoa, que havia concedido a liminar, reconhecendo o direito da Associação dos Criadores e Expositores de Raças Combatentes do Estado da Paraíba de continuar a praticar o esporte galismo, popularmente conhecido como "rinha de galo". Determinou-se, ainda, que a Sudema se abstivesse de proibir o livre exercício do "esporte", e de aplicar multas, além de suspender a eficácia de qualquer multa já aplicada, decorrente de fiscalização (Paraíba, 2011).

Ficou claro, então, que o órgão decidiu que a fiscalização das possíveis práticas de maus-tratos fica a cargo do órgão estadual, a Superintendência de Administração do Meio Ambiente - Sudema .

Segundo o relator, a rinha é proibida por lei. "O denominado 'evento esportivo', nada mais é que um acontecimento de extrema crueldade contra as aves concorrentes”. O magistrado citou, também, o parecer ministerial que destacou "ainda que os denominados galistas entendam a prática como esporte, a briga de galo, sob todos os ângulos, se constitui em ato de crueldade para com os animais, isto porque os galos, quando levados à rinha, brigam até que um deles caia prostrado ao chão e mortalmente ferido" segundo o texto do acórdão publicado no Diário da Justiça da Paraíba no dia 2 de setembro (Paraíba, 2011).

Em relação à competência da fiscalização, o juiz relator apresentou a Constituição Estadual da Paraíba, em seu artigo 227 (inciso II), como a instrução normativa que estabelece como incumbência do Estado a proteção da fauna e da flora, proibindo práticas que coloquem em risco sua função ecológica, provoquem a extinção da espécie ou submetam os animais à crueldade, sendo a Sudema o órgão responsável pela observância da legislação pertinente (Paraíba, 2011). 


\section{A FAUNA QUE NECESSITA MAIS GARANTIAS}

Em meio aos nossos recursos naturais são desenvolvidas diversas atividades criadas e voltadas exclusivamente para atender à demanda gerada pela vida do homem em sociedade. Os indivíduos desenvolvem um meio ambiente de forma que suas necessidades sejam prontamente atendidas (Escobar, 2014, p. 66).

$\mathrm{O}$ ambiente no qual antes predominava aquilo que determinava a natureza, passou a ser alvo de mudanças em prol de um desenvolvimento social, conforme observa Fiorillo (2009, p. 33).

Devido à crescente degradação relacionada a questões ambientais, fez-se necessário surgir no Direito um ramo que tratasse especificamente dessa esfera. Esse novo ramo do Direito, mais tarde conhecido como Direito Ambiental, trouxe consigo ideias referentes à tutela e preservação do meio natural.

A demora na percepção dos problemas ambientais vivenciados foi perceptível pelos legisladores brasileiros, porém a criação de um ordenamento mais voltado para a questão ambiental muda essa situação. Barros (2008, p. 3) argumenta:

Somente depois que fatos graves ocorreram, todos causados por intervenção humana na busca de um desenvolvimento industrial desmedido, $\mathrm{e}$ que vozes de peso soaram alertando que esses ataques ao meio ambiente pudessem produzir efeitos para toda a humanidade, é que se começou a tomar consciência da necessidade de se criarem organismos políticos e estruturas jurídicas para protegê-lo. Foi a partir daí que surgiu a preocupação com a implementação de normas jurídicas específicas, portanto, de um direito próprio com o claro intuito de proteger o meio ambiente.

Desta maneira, o autor deixa claro que as agressões aos recursos naturais colaboraram para a geração de institutos jurídicos específicos, e criou-se a necessidade de uma tutela especial. Ainda sobre o assunto Granziera (2009, p. 5) acentua: 
A necessidade de organizar as atividades humanas, com vistas a refrear as conseqüências que começavam a ser sentidas, deu azo ao surgimento de um novo direito, que se ocupasse sistematicamente da proteção ambiental. Nessa ótica, seu objetivo é suprimir ou limitar o impacto das atividades humanas sobre os recursos ambientais ou sobre o meio ambiente.

Até o final da década de 70 não existia ainda um perfil constitucional que tratasse de normas legais referentes ao meio ambiente. Posteriormente, na década de 80, a Lei da Política Nacional do Meio Ambiente - Lei 6.938/1981 - alavancou em seu conteúdo estas últimas ideias juntamente com a Carta Magna de 1988, que finalmente tornaram constitucionalizadas essas matérias ambientais (Brasil, 1981).

Pode-se afirmar que o direito do ambiente, por meio de princípios próprios, possui fundamento constitucional e com um regramento infraconstitucional complexo e moderno (Escobar; Aguiar, 2012, p. 278). Além disso, tem a sua disposição toda uma especializada estrutura administrativa entre os aparelhos de Estado, além de instrumentos eficazes de execução

O ordenamento jurídico brasileiro dispõe de normas - leis, decretos e portarias - que se referem à fauna nativa quando especificam a atividade da caça, regras de proteção dos animais e condições de criação. E a Constituição Federal, no artigo 225, VII trata, de um modo mais generalista, da flora e da fauna, determinando que se deve " proteger a fauna e a flora, vedadas, na forma da lei, as práticas que coloquem em risco sua função ecológica, provoquem a extinção de espécies ou submetam os animais à crueldade” (Brasil, 2008).

Assim, os animais domésticos existentes no país e também os animais silvestres - asselvajados ou ferais -, descendentes de animais domésticos, estão entre os seres vivos que devem ser protegidos contra os maus-tratos (Brasil, 2008). 
Em nosso país fica a cargo do Estado o dever de defender os animais, ainda conforme a Constituição Federal de 1988:

$\S 1^{\circ}$ - Para assegurar a efetividade desse direito, incumbe ao Poder Público: (...)VII - proteger a fauna e a flora, vedadas, na forma da lei, as práticas que coloquem em risco sua função ecológica, provoquem a extinção de espécies ou submetam os animais a crueldade (Brasil, 2008).

Nesse contexto, a atividade das brigas de galo se confronta com o dispositivo constitucional, o qual proíbe que animais sejam submetidos a práticas cruéis. A determinação do artigo 225 assegura à coletividade a garantia de um meio ambiente ecologicamente equilibrado.

Pelo texto constitucional incumbe ao poder público a tarefa de protegê-lo, de maneira que as gerações futuras também utilizem esses mesmos recursos. A fauna é, portanto, protegida nesse mesmo dispositivo, proibidas as práticas que coloquem em risco sua função ecológica, provoquem maus tratos e/ou submetam os animais à crueldade.

Proteger os animais faz parte da ética humana. Os animais deveriam ser inseridos no mesmo sistema de proteção legal concedido ao ser humano, defende Dias (2000, p. 89). Por fazer parte da dignidade humana a proteção dos animais é um dos fundamentos do Estado Democrático de Direito. Cabe concordar com a autora no sentido de que os direitos dos animais são tratados como direitos de dignidade. E muitas novas teorias já contribuem para o reconhecimento dos direitos dos animais.

\subsection{O Princípio da Precaução}

Na esfera do Direito Ambiental, alguns princípios norteiam a condução da proteção aos recursos naturais. No Brasil a fauna ainda é tutelada pelo Princípio da Precaução. A função é evitar riscos e a ocorrência 
de danos ambientais. É um dispositivo adotado por vários países com a finalidade de reconhecer a possibilidade da ocorrência de danos e a necessidade de sua avaliação com base nos conhecimentos já disponíveis.

No Brasil o Princípio da Precaução coloca-se no sistema jurídico como uma das principais defesas do meio ambiente, "senão a mais importante, tendo por consequência lógica a tutela da fauna” (Ayala, 2005, p. 163).

O entendimento do professor e procurador ambiental Patrick Ayala é no sentido de valorizar a cautela. Nas questões ambientais muitas vezes trata-se de riscos não mensuráveis, não avaliáveis. A aplicação da precaução demanda um exercício ativo da dúvida, vez que sua lógica visa ampliar a incerteza, sendo que esta não exonera de responsabilidade. Pelo contrário, ela reforça a criação de um dever de prudência.

O Princípio da Precaução deve ser interpretado em um processo de sensibilização, como aponta Romeiro (1999, p. 20):

Sua atuação, por sua vez, tem sido extremamente importante também para o aprofundamento do processo de conscientização ecológica e de mudança de valores culturais que ele implica. Nesse sentido, estão sendo criadas as condições objetivas que vão permitir o surgimento de novas instituições capazes de impor restrições ambientais que atingem mais profundamente a racionalidade econômica atual.

Nesse viés, qualquer medida de precaução em relação à fauna deve ser coordenada no sentido de tentar garantir a sua eficácia, sendo certo que tal coordenação deve se expressar pela conservação dos espaços de constatada incidência de espécies, bem como pela atuação de forma direta sobre elas e sobre seus habitats, por meio de áreas protegidas, de maneira interdependente (Bortolozi, 2011, p. 77). 
Em nosso país todos os animais, qualquer que seja o seu habitat, constituem bens ambientais vivos, integrantes dos recursos ambientais compreendidos na natureza. Assim, fazem parte do meio ambiente, sem qualquer exceção, sem discriminação ou exclusão de espécies ou categorias, consequentemente são protegidos sem discriminação pelo conjunto de normas ambientais.

Para Singer (2002, p. 69) em razão da capacidade dos animais de sentirem prazer e dor, as espécies têm interesse em não passar por sofrimentos. Assim, fica clara a posição utilitarista do filósofo, que defende os direitos dos animais.

Para Fiorillo (2009), a função ecológica é elemento determinante para que caracterize a fauna como bem de natureza difusa. Significa que esta função ecológica das espécies animais pode ser cumprida na medida em que a fauna participa da manutenção e equilíbrio do ecossistema, sendo essencial a uma qualidade de vida sadia. Como já referido, esta função ecológica da fauna é prevista na Constituição Federal, em seu artigo 225 , $\S 1^{\circ}$, VII que veda qualquer atividade contra a fauna que coloque em risco sua função ecológica.

Fica claro então que a fauna, assim como outros recursos, exerce um papel fundamental de equilíbrio no ecossistema. A proteção ofertada pela Constituição Federal é clara e compreende esta função ecológica dos animais, uma proteção em relação a sua existência na medida em que se pretende evitar as práticas que provoquem a extinção das espécies. Depreende-se do texto legal e ideias dos autores já expostos, que existe ainda a proteção à integridade física dos animais porque visa a repudiar as ações que submetam os animais à crueldade ou maus-tratos.

\section{CONCLUSÕES}

Ao analisar-se os procedimentos judiciais a que se submeteram os realizadores das rinhas, seja na tentativa de defender ou tentar legalizar a prática, percebe-se claramente o desejo de permitir as brigas. 
A pressão das entidades ambientalistas e da opinião pública também recai sobre as autoridades, para que, por meio dos órgãos ambientais, garanta uma fiscalização eficiente. Há, no entanto, situações com as quais os gestores ambientais parecem não se preocupar. Esse detalhe está na manutenção da integridade da vida animal, incluindo também a proibição da crueldade contra os animais.

Cabe ressaltar que qualquer cidadão, diante da ciência da prática de rinhas pode e deve denunciar aos órgãos ambientais, polícias, e principalmente ao Ministério Público, que pode cobrar pela inércia das autoridades competentes pelo controle ambiental.

Conclui-se que o conjunto de leis, embora não seja suficientemente severo, já seria suficiente para coibir as práticas das rinhas. Cabe ao atual ordenamento jurídico já apresentado neste texto definir as normas de salvaguarda ambiental, com a garantia de efetividade a estas regras.

Compete aos nossos legisladores de todos os âmbitos - federal, estadual e municipal - ao elaborar normas sobre a fauna, manter esta característica protetiva que o Estado brasileiro necessita ofertar aos animais, visto que são seres tutelados pelo poder público.

Cabe aos julgadores, a quem está reservada a tarefa de julgar as ações envolvendo a fauna, aplicar e interpretar, de forma ampla e irrestrita, as normas de proteção animal, sob a égide de nossa Constituição, tendo como princípio a proteção da fauna brasileira.

\section{REFERÊNCIAS}

ALBUQUERQUE JR., Durval Muniz. A invenção do Nordeste e outras artes. 4 . ed. Recife: FNJ; Ed. Massangana; São Paulo: Cortez, 2009. 
AYALA, Patryck de Araújo. O princípio da precaução e a proteção jurídica da fauna na Constituição Brasileira. Revista do Direito Ambiental, 39, ano 10, jul./set. 2005.

AS DECISÕES histriônicas e as decisões sérias de Jânio Quadros. Revista Veja, 20/8/2011. Disponível em <http://veja.abril.com.br/noticia/brasil/sete-meses-na-montanha-russa>. Acesso em: maio 2013.

BARBOSA, Erivaldo Moreira; AGUIAR, José Otávio. História, direito e meio ambiente: diálogos possíveis. Revista Direito e Liberdade, Mossoró, RN: Esmarn, v. 8, n. 1, p. 87-116, jan./dez. 2008.

BARROS, Wellington Pacheco. Curso de direito ambiental. 2. ed. São Paulo: Atlas, 2008.

BECHARA, Érika. A proteção da fauna sob a ótica constitucional. São Paulo: Juarez de Oliveira, 2003.

BORTOLOZI, Emerson. A tutela da fauna silvestre como efetivação do direito fundamental ao meio ambiente Unifieo - Centro. 2011. Dissertação (Mestrado). Disponível em: <http://www.unifieo.br/files/download/site/mestradodireito/ bibliotecadigital/dissertacoes2011/EMERSON_BORTOLOZI.pdf $>$. Acesso em: maio 2012.

BRASIL. Constituição de 1988. Constituição da República Federativa do Brasil. Brasília, DF: Senado Federal, 2008.

. Lei $\mathrm{n}^{0}$ 9605, 1998. Lei de Crimes Ambientais. São Paulo: Saraiva, 2003.

. Decreto $n^{\circ} 24.645$, de 10 de julho de 1934. Dispõe sobre penas para maus tratos aos animais. Disponível em: <http://www6.senado.gov.br/ sicon/>. Acesso em: jun. 2011a.

Decreto 50.620, de 18 de maio de 1961. "Proíbe o funcionamento das rinhas de ‘brigas de galos' e dá outras providências”. Disponível em: $<\mathrm{http}$ :// www6.senado.gov.br/legislacao/ListaNormas.action?numero=50620\&tipo_nor ma=DEC\&data $=19610518 \& l i n k=\mathrm{s}>$. Acesso em: set. $2011 \mathrm{~b}$. 
. Decreto-lei $\mathrm{n}^{\circ} 3.688$, de 3 de outubro de 1941. Lei das contravenções penais. Disponível em: <http://www.planalto.gov.br/ccivil/Decreto-Lei/ Del3688.htm>. Acesso em: jun. 2011c.

. Lei nº 6.938, de 31 de agosto de 1981. Dispõe sobre a Política Nacional do Meio Ambiente, seus fins e mecanismos de formulação e aplicação, e dá outras providências. Disponível em: <http://www.planalto.gov.br/ccivil_03/ leis/16938.htm>. Acesso em dez 2014.

DIAS, Edna Cardozo. Tutela jurídica dos animais. São Paulo: Mandamentos, 2000 .

ESCOBAR, Marco Lunardi. As rinhas de galo na Paraíba: aspectos histórico-legais e a falta de proteção aos animais. Campina Grande, 2015. 210f. Tese (Doutorado em Recursos Naturais) - UFCG, Programa de Pós-Graduação em Recursos Naturais, 2014.

ESCOBAR, Marco Lunardi; AGUIAR, José Otávio. O direito animal em face da espetacularização. O caso das rinhas de galo no nordeste brasileiro: Isso é manifestação cultural? Revista Uniabeu, Belford Roxo, v. 5, n. 10, 2012.

FERNANDES, Socorro. Depoimento [junho. 2014]. Entrevistador M. L. Escobar. Entrevista da presidente da Associação Paraibana de Proteção à Natureza concedida para elaboração de Tese de Doutorado ao Programa de Pós-Graduação em Recursos Naturais da Universidade Federal de Campina Grande. Joao Pessoa, 2014

FIORILLO, Celso A. Pacheco. Curso de direito ambiental brasileiro. 9. ed. São Paulo: Saraiva, 2009.

GONÇALVES, Maurício. A polêmica das brigas de galo: adeptos da prática insistem em dizer que não há lei que proíba os embates. Jornal Gazeta de Alagoas. Maceió, 14 jan. 2011. Editoria Geral, Caderno 1, p. 29.

GRANZIERA, Maria. Luiza Machado. Direito ambiental. São Paulo: Atlas, 2009. HIRATA, Giselle. Como é realizada uma briga de galo? Revista Mundo Estranho, 10. ed. São Paulo: Ed Abril, 2008. 
LIMA, Racil. Direito dos animais. Aspectos históricos, éticos e jurídicos. Associação Nacional dos Analistas do Poder Judiciário e do Ministério Público da União. 2009. Disponível em: <http://anajus.org/home/index.php?option=com_content\&view=article $\& i d=686 \% 3 A 15102009$-direito-dos-animais-aspectos-historicos-eticos-e-juridicos-por-racil-de-lima\&catid=23\%3Aartigos\&Itemid=16\#_Toc211321245>. Acesso em: maio 2012.

MILARÉ, Édis. Direito do ambiente. São Paulo: Revista dos Tribunais, 2004. NOTA do Ibama à população paraibana sobre as rinhas de galo. Notícia. 4 de novembro de 2009. Website. Disponível em: <http://www.ibama.gov.br/ noticias-2009/nota-do-ibama-a-populacao-paraibana-sobre-as-rinhas-de-galo> . Acesso em: maio 2013.

ORGANIZAÇÃO DAS NAÇÕS UNIDAS. ONU. Declaração Universal dos Direitos dos Animais. Proclamada em Assembleia da Unesco em Bruxelas, Bélgica, no dia 27 de Janeiro de 1978. Disponível em: <http://www.propq.ufscar.br/ comissoes-de-etica/comissao-de-etica-na-experimentacao-animal/direitos>. Acesso em: maio 2012.

ONU. Declaração do Rio de Janeiro de 1992. Documento resultante da Conferência das Nações Unidas sobre Meio Ambiente e Desenvolvimento, Disponível em <www.onu.org.br/rio20/img/2012/01/rio92.pdf $\square>$ Acesso em: 19 maio 2013.

PARAÍBA. Diário da justiça. Edição de 6 de agosto de 2009, p. 17. João Pessoa, PB: Poder Judiciário, 2009.

PARAÍBA. Diário da Justiça. Edição de 2 de setembro de 2011, seção 1, p. 29. João Pessoa - PB: Poder Judiciário, 2011.

PAZ, Ronilson José. Depoimento [setembro. 2013]. Entrevistador M. L. Escobar. Entrevista do analista ambiental e ex-superintendente do Ibama na Paraíba concedida para elaboração de Tese de Doutorado ao Programa de Pós-Graduação em Recursos Naturais da Universidade Federal de Campina Grande, Joao Pessoa.

ROMEIRO, Ademar R. Desenvolvimento sustentável e mudança institucional: notas preliminares. Texto para discussão, IE/Unicamp, Campinas, 1999. 
SINGER, Peter. Ética prática. Lisboa: Gradiva, 2002. . Libertação animal. Porto Alegre: Lugano, 2004.

THOMAS, Keith. O homem e o mundo natural. São Paulo: Cia das Letras, 2010.

Recebido em: 6/2/2014

Aceito em: 20/3/2014 